\title{
A Study of Exhaust Emission Techniques and Changing the Structure in Catalytic Converter
}

\author{
R. Manoj Kumar ${ }^{1}$ M.E., S. Arulkumar ${ }^{2}$ M.E., M. Harish Kumar ${ }^{3}$ B.E., B. Sasidharan ${ }^{4}$ B.E \\ ${ }^{1,2}$ Assistant Professor, Department of Automobile Engineering, Dr. Mahalingam College Of Engineering and Technology (Autonomous), \\ Pollachi, TamilNadu \\ ${ }^{3,4}$ Final Year, Department of Automobile Engineering, Dr. Mahalingam College Of Engineering and Technology (Autonomous), Pollachi, \\ TamilNadu
}

\begin{abstract}
In the next few years air pollution, the stringency of NOx-and other gas-emissions have been increased twice in the last decade and emerging technologies in emission controls has been recommended. We focused on Catalytic convertor structure design and tried Catalytic convertor structure with spinel from the honey comb. By changing the structure the contact area and time of contact of exhaust gases with ceramic layer substrate. If these things were done, the emission is reduced to some extent. Our project mainly focused on increasing contact area of exhaust gases to spinel structure. The structure has been changed and its strength was analyzed using ANSYS software.
\end{abstract}

Keywords: Spinel structure, Design of Catalytic converter

\section{Introduction}

The monolithic catalytic converter remains the main pollution control device for modern automobiles towards reaching the ever-increasing legislative demands for low emission standards. The catalytic converter is expected to attain conversion efficiencies of the order of $95 \%$ or above for the main exhaust gas pollutants, namely $\mathrm{CO}$, hydrocarbons and NOx. The conversion efficiency is a function of numerous design and operating parameters of the complete system, comprising the engine, the exhaust line and the catalytic converter. The design optimization task is especially demanding due to the highly unsteady conditions in the engine exhaust regarding temperature, flow rate and exhaust composition.

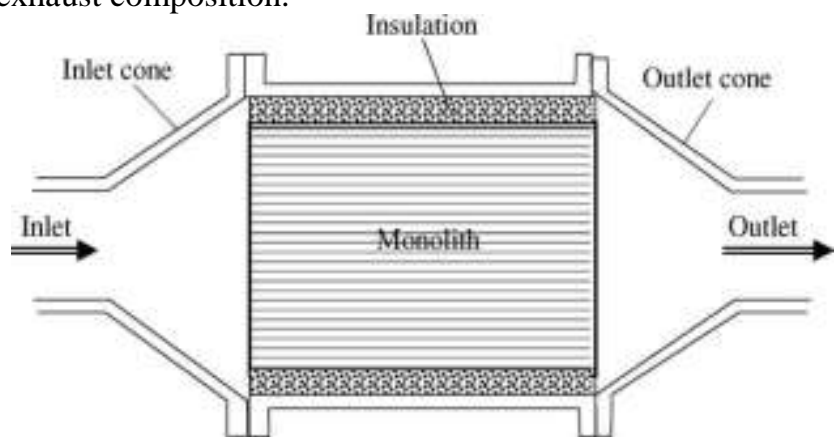

Figure 1.1

\section{Catalytic Converter}

A catalytic converter (colloquially, "cat" or "catcon") is a vehicle emissions control device which converts toxic byproducts of combustion in the exhaust of an internal combustion engine to less toxic substances by way of catalyzed chemical reactions.

A substrate is a substance on which some substance is absorbed. (Catalytic conversion requires a precisely balanced air-to-fuel ratio, hence the need for oxygen sensors.) In dual-bed converter systems the exhaust gases are first reduced in order to eliminate the oxides of nitrogen; then they are oxidized with added air in order to eliminate carbon monoxide and unburned hydrocarbons. In more advanced three-way converters individual catalysts accomplish reduction of each species simultaneously. Catalysts are either platinum-group metals or base metals such as chromium, nickel, and copper. Platinum-group metals or noble metals are any of several metallic chemical elements that have outstanding resistance to oxidation, even at high temperatures. In base-metal catalysts the active surfaces are actually ceramic oxides of the metals. Because platinum metals are extremely expensive, they are deposited on ceramic catalyst supports as salts and then reduced to finely divide metal particles. For efficiency of conversion, extremely large surface areas are required. These are accomplished by ingenious micro-structural engineering of the ceramic support structure

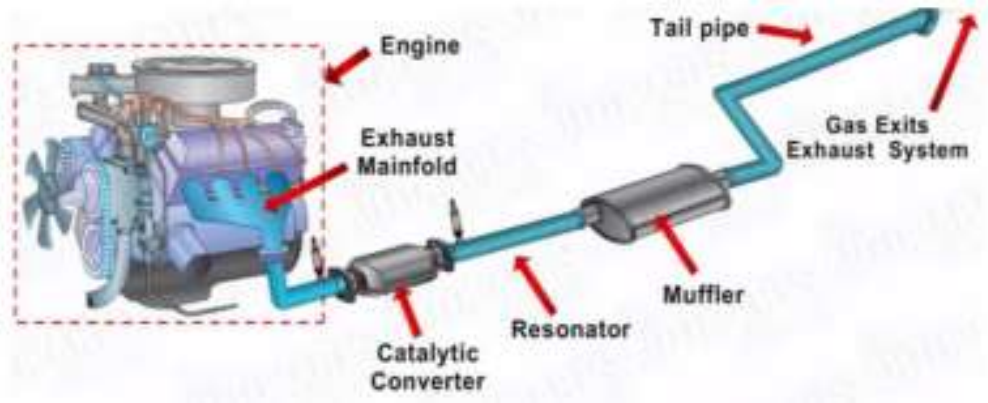

Figure 2.1

Volume 6 Issue 12, December 2017 www.ijsr.net 


\section{International Journal of Science and Research (IJSR) \\ ISSN (Online): 2319-7064 \\ Index Copernicus Value (2016): 79.57 | Impact Factor (2015): 6.391}

\subsection{Types of Catalytic Converters}

\subsubsection{Two-way}

A two-way (or "oxidation") catalytic converter has two simultaneous tasks:
- Oxidation of carbon monoxide to carbon dioxide: $2 \mathrm{CO}+$ $\mathrm{O} 2 \rightarrow 2 \mathrm{CO} 2$

- Oxidation of hydrocarbons (unburnt and partially burnt fuel) to carbon dioxide and water: (a combustion reaction)

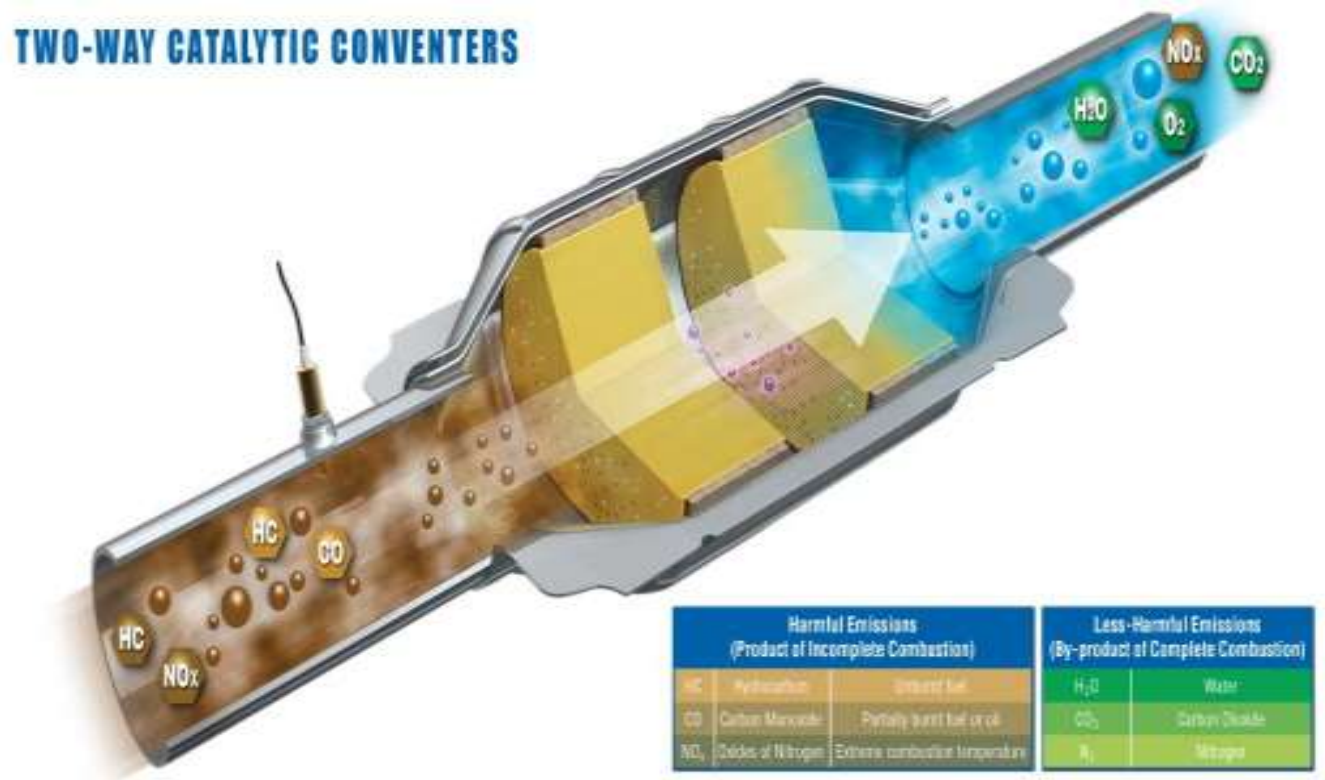

Figure 2.2

This type of catalytic converter is widely used on diesel engines to reduce hydrocarbon and carbon monoxide emissions. Because of their inability to control oxides of nitrogen, they were superseded by three-way converters.

\subsubsection{Three-way}

A three-way catalytic converter has three simultaneous tasks:

- Reduction of nitrogen oxides to nitrogen and oxygen: $2 \mathrm{NOx} \rightarrow \mathrm{xO} 2+\mathrm{N} 2$

- Oxidation of carbon monoxide to carbon dioxide: $2 \mathrm{CO}+$ $\mathrm{O} 2 \rightarrow 2 \mathrm{CO} 2$
- Oxidation of unburnt hydrocarbons (HC) to carbon dioxide and water.

These three reactions occur most efficiently when the catalytic converter receives exhaust from an engine running slightly above the stoichiometric point. This point is between 14.6 and 14.8 parts air to 1 part fuel, by weight, for gasoline. In general, engines fitted with 3-way catalytic converters are equipped with a computerized closed-loop feedback fuel injection system using one or more oxygen sensors, though early in the deployment of three-way converters, carburetors equipped for feedback mixture control were used.

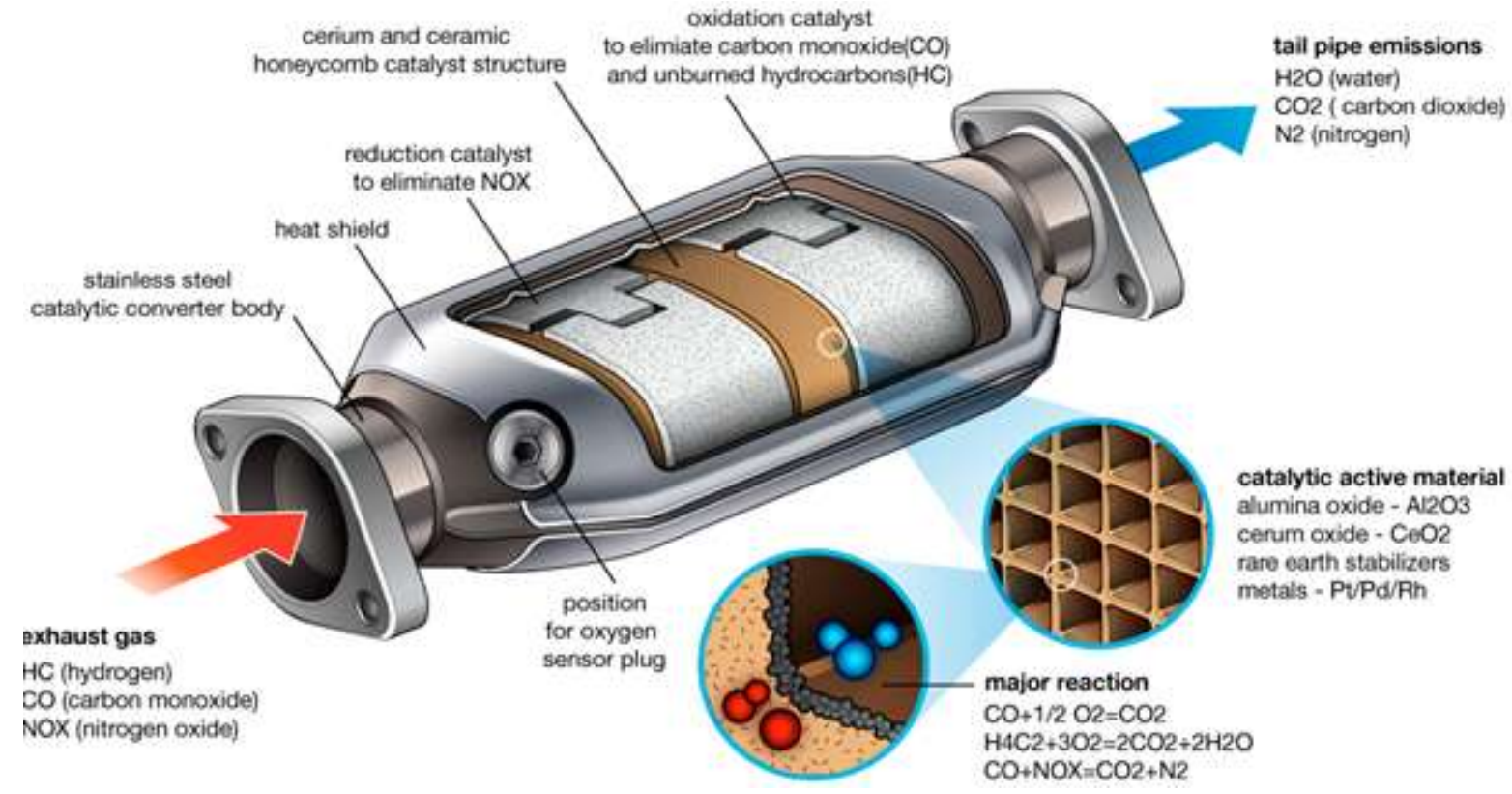

Figure 2.3

Volume 6 Issue 12, December 2017 www.ijsr.net 


\section{International Journal of Science and Research (IJSR) \\ ISSN (Online): 2319-7064}

Index Copernicus Value (2016): 79.57 | Impact Factor (2015): 6.391

Three-way catalysts are effective when the engine is operated within a narrow band of air-fuel ratios near stoichiometry, such that the exhaust gas oscillates between rich (excess fuel) and lean (excess oxygen) conditions. However, conversion efficiency falls very rapidly when the engine is operated outside of that band of air-fuel ratios. Under lean engine operation, there is excess oxygen and the reduction of NOx is not favored. Under rich conditions, the excess fuel consumes all of the available oxygen prior to the catalyst, thus only stored oxygen is available for the oxidation function. Closed-loop control systems are necessary because of the conflicting requirements for effective NOx reduction and $\mathrm{HC}$ oxidation. The control system must prevent the NOx reduction catalyst from becoming fully oxidized, yet replenish the oxygen storage material to maintain its function as an oxidation catalyst.

Three-way catalytic converters can store oxygen from the exhaust gas stream, usually when the air-fuel ratio goes lean. When insufficient oxygen is available from the exhaust stream, the stored oxygen is released and consumed. A lack of sufficient oxygen occurs either when oxygen derived from NOx reduction is unavailable or when certain maneuvers such as hard acceleration enrich the mixture beyond the ability of the converter to supply oxygen.

Unwanted reactions can occur in the three-way catalyst, such as the formation of hydrogen sulfide and ammonia. Formation of each can be limited by modifications to the washcoat and precious metals used. It is difficult to eliminate these byproducts entirely. Sulphur-free or lowSulphur fuels eliminate or reduce hydrogen sulfide.

\section{Catalyst in Catalytic Converter}

A catalyst is a substance that causes or accelerates a chemical reaction without itself being affected. Catalysts participate in the reactions, but are neither reactants nor products of the reaction they catalyze.

There are two different types of catalysts in a catalytic converter. A reduction catalyst and an oxidation catalyst. Both consist of a ceramic structure coated with a metal catalyst, usually platinum, rhodium or palladium. This creates a structure that exposes the maximum surface area of catalyst to the exhaust stream, whilst minimizing the amount of catalyst required. Some of the new converters have started to use gold mixed with the traditional catalysts which could increase oxidation.

Most modern cars are equipped with three-way catalytic converters. This refers to the three regulated emissions it helps to reduce.

The reduction catalyst is the first stage of the catalytic converter. It uses platinum and rhodium to help reduce the NOx emissions. When an NO or NO2 molecule contacts the catalyst, the catalyst rips the nitrogen atom out of the molecule and holds on to it, freeing the oxygen in the form of $\mathrm{O} 2$. The nitrogen atoms bond with other nitrogen atoms that are also stuck to the catalyst, forming N2. For example: $2 \mathrm{NO} \rightarrow \mathrm{N} 2+\mathrm{O} 2$ or $2 \mathrm{NO} 2 \rightarrow \mathrm{N} 2+2 \mathrm{O} 2$

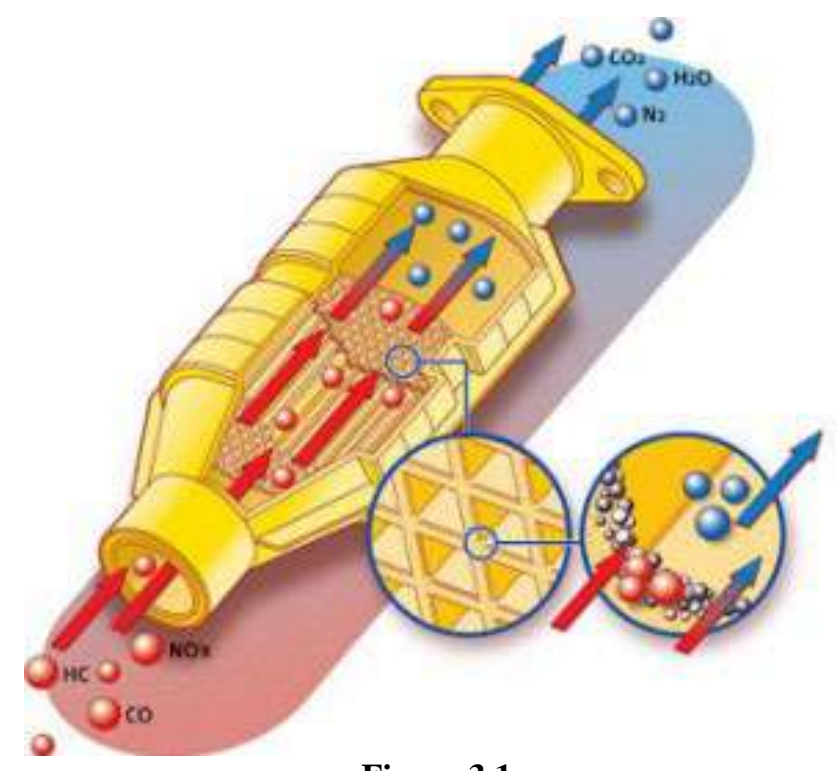

Figure 3.1

Ceramic honeycomb catalyst structure. The oxidation catalyst is the second stage of the catalytic converter. It reduces the unburned hydrocarbons and carbon monoxide by burning (oxidizing) them over a platinum and palladium catalyst. This catalyst aids the reaction of the $\mathrm{CO}$ and hydrocarbons with the remaining oxygen in the exhaust gas.

$$
2 \mathrm{CO}+\mathrm{O} 2 \rightarrow 2 \mathrm{CO} 2
$$

There are two main types of structures used in catalytic converters - honeycomb and ceramic beads. Most cars today use a honeycomb structure.

\section{Techniques of NOX Reduction}

\section{Types of Techniques}

- Low excess air (LEA) combustion

- Exhaust gas recirculation (EGR)

- Staged Combustion (SC)

- Flue Gas Recirculation (FGR)

- Low NOx Burners (LNB)

- NOX Reburning

- Selective Catalytic Reduction (SCR)

- Selective Non-catalytic Reduction (SNCR)

- Reciprocating Internal Combustion Engines (RICE)

\subsection{Exhaust Gas Recirculation (EGR)}

In internal combustion engines, exhaust gas recirculation (EGR) is a nitrogen oxide $\left(\mathrm{NO}_{\mathrm{x}}\right)$ emissions reduction technique used in petrol/gasoline and diesel engines. EGR works by recirculating a portion of an engine's exhaust gas back to the engine cylinders. This dilutes the $\mathrm{O}_{2}$ in the incoming air stream and provides gases inert to combustion to act as absorbents of combustion heat to reduce peak incylinder temperatures. NOx is produced in a narrow band of high cylinder temperatures and pressures.

In a gasoline engine, this inert exhaust displaces the amount of combustible matter in the cylinder. In a diesel engine, the exhaust gas replaces some of the excess oxygen in the precombustion mixture. Because NOx forms primarily when a

Volume 6 Issue 12, December 2017 


\section{International Journal of Science and Research (IJSR) \\ ISSN (Online): 2319-7064 \\ Index Copernicus Value (2016): 79.57 | Impact Factor (2015): 6.391}

mixture of nitrogen and oxygen is subjected to high temperature, the lower combustion chamber temperatures caused by EGR reduces the amount of NOx the combustion generates (though at some loss of engine efficiency). Gases re-introduced from EGR systems will also contain near equilibrium concentrations of $\mathrm{NOx}$ and $\mathrm{CO}$; the small fraction initially within the combustion chamber inhibits the total net production of these and other pollutants when sampled on a time average. Most modern engines now require exhaust gas recirculation to meet emissions standards. Chemical properties of different fuels limit how much EGR may be used. For example methanol is more tolerant to EGR than gasoline. However, the EGR can affect the NOx reduction in three possible ways:

- Reduced throttling losses. The addition of inert exhaust gas into the intake system means that for a given power output, the throttle plate must be opened further, resulting in increased inlet manifold pressure and reduced throttling losses.

- Reduced heat rejection. Lowered peak combustion temperatures not only reduces NOx formation, it also reduces the loss of thermal energy to combustion chamber surfaces, leaving more available for conversion to mechanical work during the expansion stroke.

- Reduced chemical dissociation. The lower peak temperatures result in more of the released energy remaining as sensible energy near TDC (Top DeadCenter), rather than being bound up (early in the expansion stroke) in the dissociation of combustion products. This effect is minor compared to the first two.

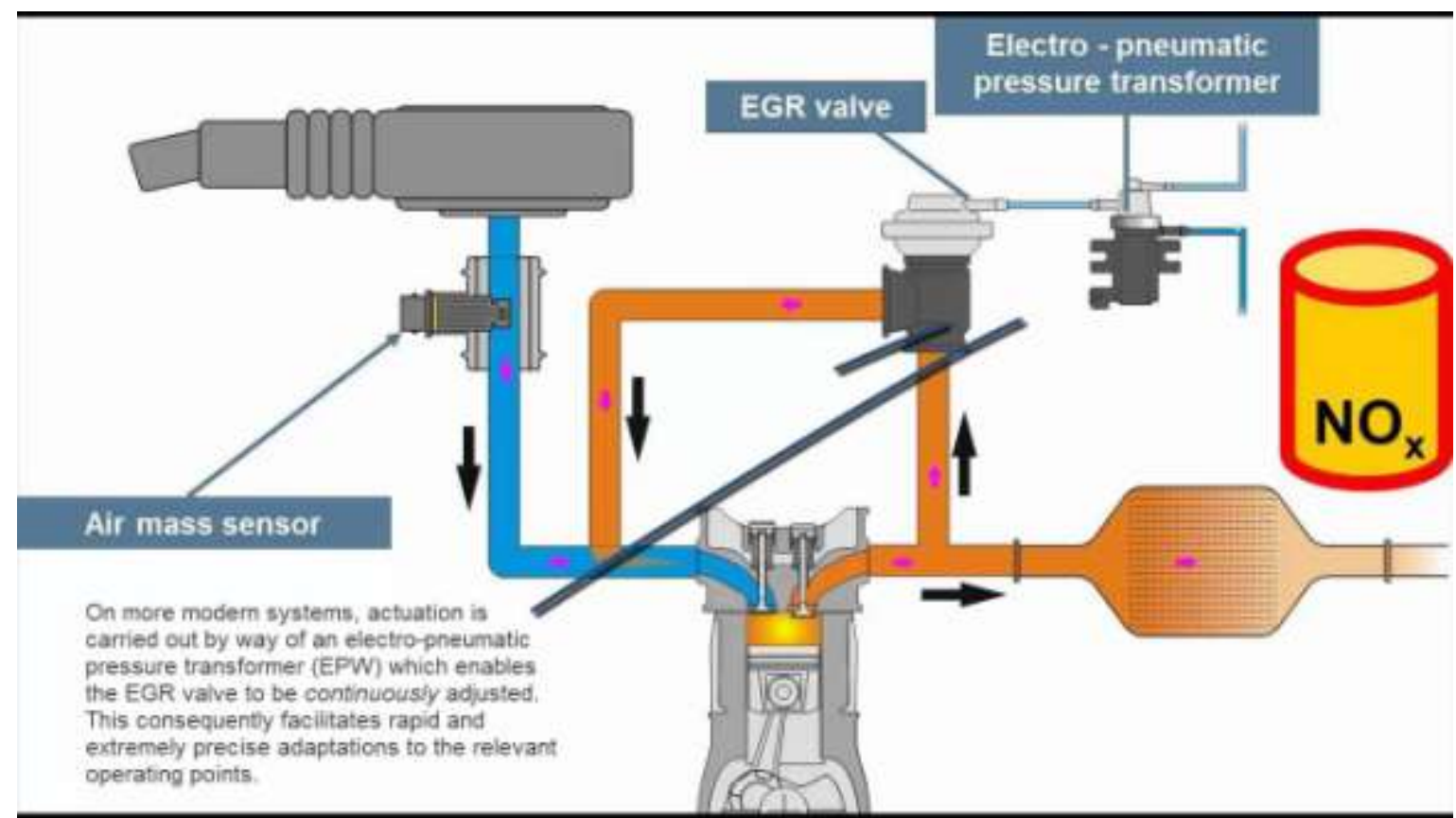

Figure 4.1

\subsection{Selective Catalytic Reduction (SCR):}

Selective catalytic reduction (SCR) is a means of converting nitrogen oxides, also referred to as NOx with the aid of a catalyst into diatomic nitrogen (N2), and water (H2O). A gaseous reductant, typically anhydrous ammonia, aqueous ammonia or urea, is added to a stream of flue or exhaust gas and is adsorbed onto a catalyst. Carbon dioxide, $\mathrm{CO} 2$ is a reaction product when urea is used as the reductant.

Commercial selective catalytic reduction systems are typically found on large utility boilers, industrial boilers, and municipal solid waste boilers and have been shown to reduce NO $x$ by $70-95 \%$. More recent applications include diesel engines, such as those found on large ships, diesel locomotives, gas turbines, and even automobiles.

The NOx reduction reaction takes place as the gases pass through the catalyst chamber. Before entering the catalyst chamber the ammonia, or other reductant (such as urea), is injected and mixed with the gases. The chemical equation for a stochiometric reaction using either anhydrous or aqueous ammonia for a selective catalytic reduction process is:

$4 \mathrm{NO}+4 \mathrm{NH} 3+\mathrm{O} 2 \rightarrow 4 \mathrm{~N} 2+6 \mathrm{H} 2 \mathrm{O}$

$2 \mathrm{NO} 2+4 \mathrm{NH} 3+\mathrm{O} 2 \rightarrow 3 \mathrm{~N} 2+6 \mathrm{H} 2 \mathrm{O}$

$\mathrm{NO}+\mathrm{NO} 2+2 \mathrm{NH} 3 \rightarrow 2 \mathrm{~N} 2+3 \mathrm{H} 2 \mathrm{O}$

With several secondary reactions:

$2 \mathrm{SO} 2+\mathrm{O} 2 \rightarrow 2 \mathrm{SO} 3$

$2 \mathrm{NH} 3+\mathrm{SO} 3+\mathrm{H} 2 \mathrm{O} \rightarrow(\mathrm{NH} 4) 2 \mathrm{SO} 4$

$\mathrm{NH} 3+\mathrm{SO} 3+\mathrm{H} 2 \mathrm{O} \rightarrow \mathrm{NH} 4 \mathrm{HSO} 4$

The reaction for urea instead of either anhydrous or aqueous ammonia is:

$4 \mathrm{NO}+2(\mathrm{NH} 2) 2 \mathrm{CO}+\mathrm{O} 2 \rightarrow 4 \mathrm{~N} 2+4 \mathrm{H} 2 \mathrm{O}+2 \mathrm{CO} 2$ 
International Journal of Science and Research (IJSR)

ISSN (Online): 2319-7064

Index Copernicus Value (2016): 79.57 | Impact Factor (2015): 6.391

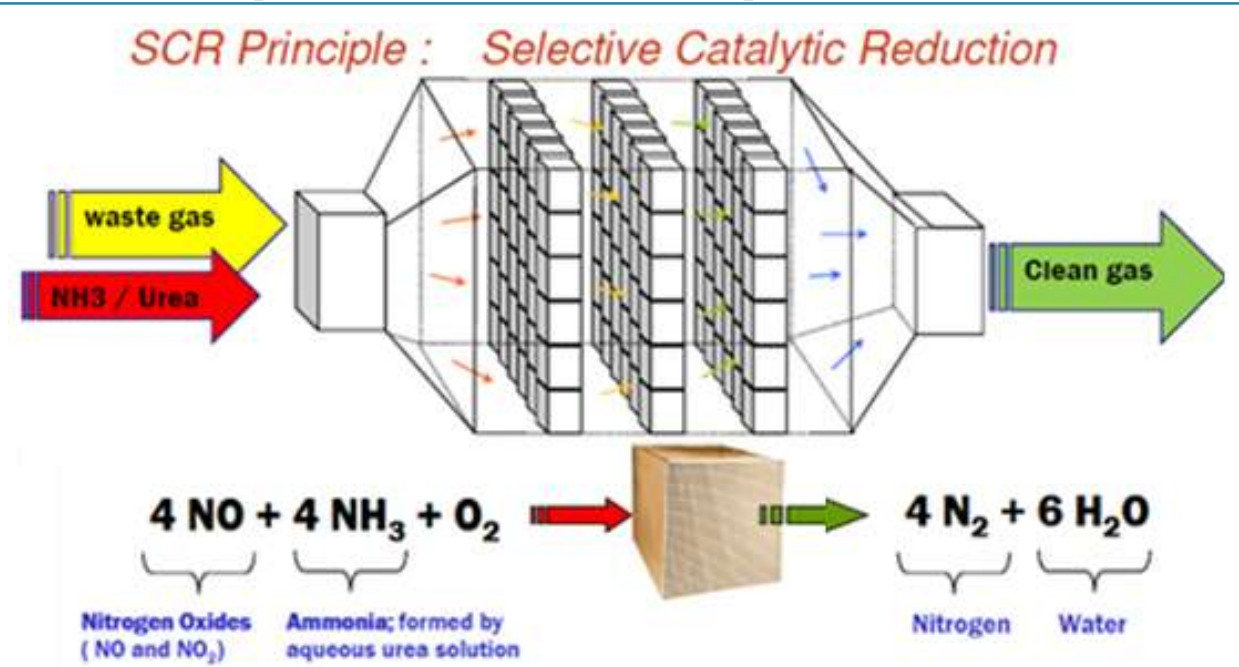

Figure 4.2(a)

The ideal reaction has an optimal temperature range between 630 and $720 \mathrm{~K}$, but can operate from 500 to $720 \mathrm{~K}$ with longer residence times. The minimum effective temperature depends on the various fuels, gas constituents, and catalyst geometry. Other possible reductants include cyanuric acid and ammonium sulfate.

NOx is considered a harmful greenhouse gas and substantial releases into the atmosphere are prohibited. The abatement system is configured with a NOx reducing catalyst and an ammonia injection system. The catalytic reaction of the ammonia across the Selective Catalytic Reducer (SCR) reduces the emission of NOx by converting it into basic atmosphere elements (nitrogen, oxygen, and water). The catalyst comes in varying arrangements depending on the application.

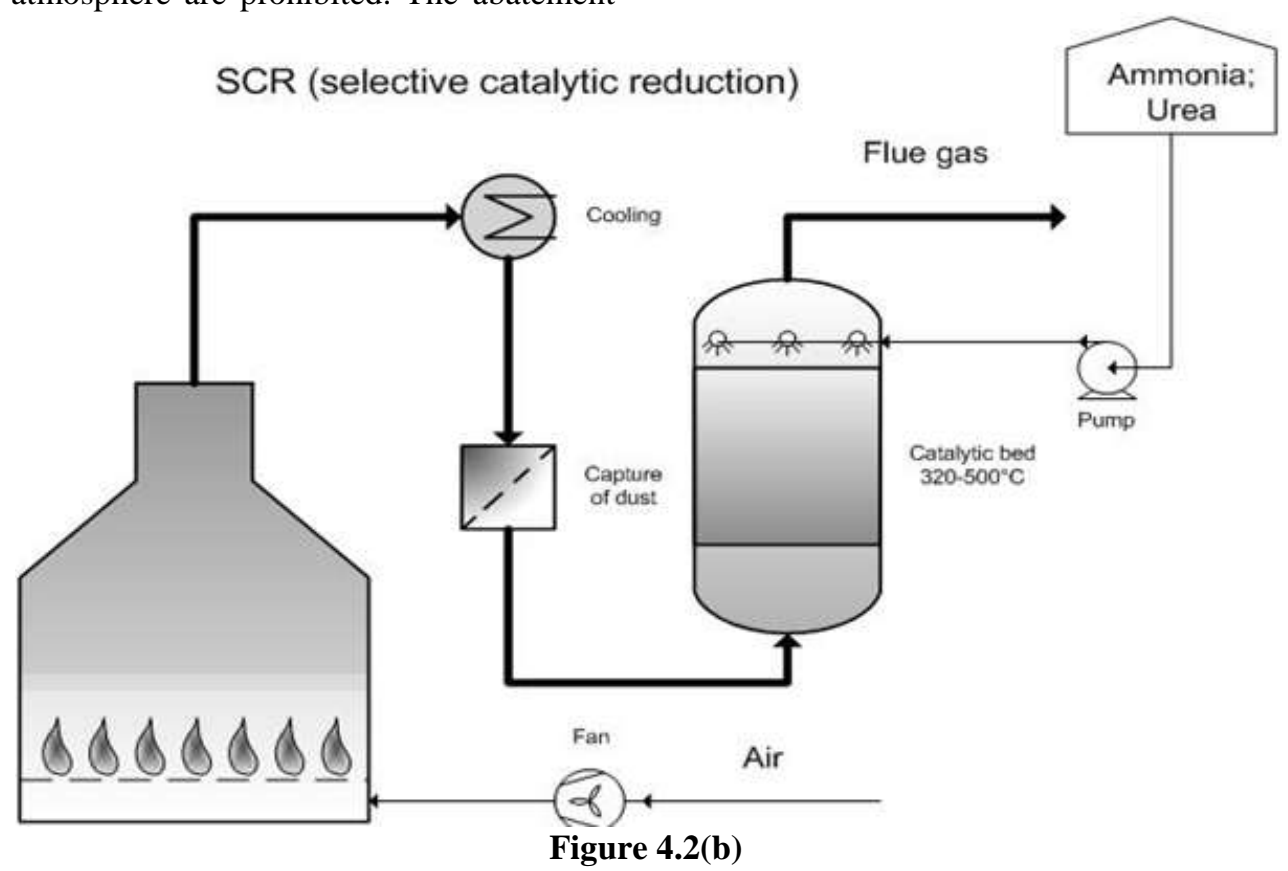

The ammonia injection system allows ammonia to be introduced to the process to combine with the process NOx and reduce the amount of NOx emitted from the system. An Ammonia Flow Control Unit (AFCU) and Ammonia Injection Grid (AIG) provide a controlled supply of anhydrous ammonia as dictated by a NOx and Ammonia (NH3) analyzer system.

\subsection{NOx Reburning}

Reburning is a NOx staged combustion control technique that suppresses the formation of NOx in burners and then provides for additional NOx reduction in the furnace area of the boiler. Reburning can be applied to any type of boiler, provided the gas stream residence time is long enough to allow the reburn fuel to burn completely. NOx reductions of $50 \%$ to $70 \%$ are possible. Reburning can be used in combination with a number of other NOx control techniques. NOx reburning is also called reburn, in-furnace NOx reduction, and staged fuel injection.

\subsection{Summary of NOx Reduction Techniques}

\title{
Volume 6 Issue 12, December 2017
}

\author{
www.ijsr.net
}


International Journal of Science and Research (IJSR)

ISSN (Online): 2319-7064

Index Copernicus Value (2016): 79.57 | Impact Factor (2015): 6.391

\begin{tabular}{|l|l|}
\multicolumn{1}{|c|}{$\begin{array}{c}\text { NO } \\
\text { Technique } \\
\text { Techlion }\end{array}$} & \multicolumn{1}{|c|}{$\begin{array}{c}\text { NO }_{x} \text { Reduction } \\
\text { Achieved }\end{array}$} \\
\hline Less generator testing & \\
\hline Generator fuel switch & \\
\hline LEA $(\sim 2-7 \%)$ & $16-20 \%$ \\
\hline SC & $20 \%$ \\
\hline $\begin{array}{l}\text { SC }(\sim 25-30 \% \\
\text { burners out of service; } \\
\text { BOOS })\end{array}$ & $30-40 \%$ \\
\hline FGR & $15 \%$ \\
\hline LNB & $20-50 \%$ \\
\hline Reburning & $50-70 \%$ \\
\hline SCR & $50-90 \%$ \\
\hline SNCR & $50 \%$ \\
\hline RICE & $\begin{array}{l}\text { Low emissions }(2.3- \\
3.2 \mathrm{lb} / \mathrm{mmBt} \text { range })\end{array}$ \\
\hline
\end{tabular}

\section{Catalytic Converter Materials}

The three primary pollutants are $\mathrm{HC}, \mathrm{CO}$, NOX these gasses pass through the catalytic converter which utilizes the sophisticated precious metals coated substrate, the coated substrate is used as a catalyst for converting the pollutants into $\mathrm{CO} 2$ and water vapor.

Automotive catalytic converter is usually a ceramic monolith with a honeycomb structure is required or either the material is designed to provide a large surface area. Metallic foil monoliths made of Kanthal ( $\mathrm{FeCrAl})$ are used in applications where particularly high heat resistance.

There are only two types of catalysts, reduction catalyst which reduces the NOX into $\mathrm{N} 2$ and $\mathrm{O} 2$ and oxidation catalyst which oxidizes the $\mathrm{HC}$ and $\mathrm{CO}$ into $\mathrm{CO} 2$ and $\mathrm{H} 2 \mathrm{O}$. The catalyst used in reduction process is Rhodium and for oxidation process Platinum, Palladium, cerium (for enhancing the oxidation Efficiency) is used.

\subsection{Properties of Platinum}

The role of platinum in catalytic converters is to oxidize carbon monoxide (CO) and hydrocarbons. Platinum is particularly effective at this under oxygen-excessive conditions, so is often the metal of choice for diesel applications. For petrol powered vehicles (where there is a balance between reductants and oxidants in the exhaust gas), platinum and palladium can be equally effective, and so the choice is often made on the basis of relative cost. The threeway catalyst used for petrol vehicles must also be able to reduce NOx to nitrogen as well as oxidize $\mathrm{CO}$ and hydrocarbons - that is why rhodium is generally used in addition to platinum or palladium. Of course, some of the other transition elements are also capable of catalyzing oxidation reactions.

However, platinum has several advantages:

- It has a high melting point;

- Its interactions with 'poisons' (such as Sulphur compounds) are limited to the metal surface;

\section{Volume 6 Issue 12, December 2017}

Although its high melting point may seem irrelevant, because the platinum will never come close to that temperature during use, it does provide an indication of its overall thermal durability. In a catalytic converter, the metal is in the form of nano particles, which are dispersed over the entire surface of a highly porous support material. As the temperature of the catalyst rises, the particles start to become mobile and can coalesce this is called sintering, and becomes particularly noticeable as the metal approaches its Tammann temperature, at which bulk mobility of the metal particles becomes measurable. This temperature is often taken to be half the material's melting point on the absolute temperature scale. Metals such as gold and silver have temperature that is well below the average exhaust-gas temperature (600$700^{\circ} \mathrm{C}$ ) for a petrol car being driven on a motorway, and so this precludes their use in three-way catalysts.

\section{Emissions \\ 6.1 Carbon Monoxide}

Carbon monoxide (CO) is a product of incomplete combustion and occurs when carbon in the fuel is partially oxidized rather than fully oxidized to carbon dioxide (CO). Carbon monoxide reduces the flow of oxygen in the blood stream and is particularly dangerous to persons with heart disease.

\subsection{Hydrocarbons}

Hydrocarbon emissions result when fuel molecules in the engine do not burn or burn only partially. Hydrocarbons react in the presence of nitrogen oxides and sunlight to form ground-level ozone, a major component of smog. Ozone irritates the eyes, damages the lungs, and aggravates respiratory problems. It is our most widespread and intractable urban air pollution problem. A number of exhaust hydrocarbons are also toxic, with the potential to cause cancer.

\subsection{Nitrogen Oxides (NOx):}

Under the high pressure and temperature conditions in an engine, nitrogen and oxygen atoms in the air react to form various nitrogen oxides, collectively known as NOx. Nitrogen oxides, like hydrocarbons, are precursors to the formation of ozone. They also contribute to the formation of acid rain.

\subsection{Sulphur Oxides $\left(\mathrm{SO}_{\mathrm{x}}\right)$ :}

Sulphur oxides generally accelerate metal corrosion. There are several effects of acid rain that are disturbing. First, there is an acidification of a natural water sources. This can have a devastating effect on fish life. The demineralization can lead to loss in productivity of environment.

\section{Literature Survey}

Research Papers And Journals:

1. Effect of creating turbulence on performance of catalytic converter. Mohit Bhadwal - 2015. 


\title{
International Journal of Science and Research (IJSR) \\ ISSN (Online): 2319-7064
}

Index Copernicus Value (2016): 79.57 | Impact Factor (2015): 6.391

Larger contact area with catalyst in catalytic converter increases the Effectiveness of the converter by improving

\author{
the residence time of Redox reaction.
}

\section{ct of Creating Turbulence on the Performance of alytic Converter}

\author{
MANTHAN KUMAR, MOHIT BHANDWAL, MANISH SHARMA, ANMOL \\ VERMA, UTKARSH SRIVASTAVA and RAM K. TYAGI \\ Amity University Uttar Pradesh, India \\ (Received on July 25, 2015, Revised on October 29, 2015)
}

\begin{abstract}
This paper presents the effects of implementing turbulence device on the effectiveness of catalytic converter which represents the reduction in pollution rate through vehicles by minimizing the harmful emissions. This effectiveness basically deals with the rate of redox reactions of exhaust gases with the catalysts present inside the catalytic converter such as palladium ( $\mathrm{Pd})$, platinum $(\mathrm{Pt})$ and thodium $(\mathrm{Rh})$. Chief purpose of the turbulence is to increase the catalytic reactions in the catalytic converter for cleaner emissions. Devices used are designed in such a manner that they don't cause any backpressure on the combustion system that might affect the engine performance. By creating turbulence just before the catalytic converter, it creates high degree of randomness in the exhaust gases particles and due to this random movement they face larger contact area with the catalysts inside the catalytic converter and thus improves the effectiveness of the catalytic converter by increasing the rate of redox reactions. Different sets of readings has been recorded by noting down the pre and post position temperatures of the catalytic converter at different engine speeds and analyzed to obtain the best out of the designed turbulence devices.
\end{abstract}

2. Performance analysis of catalytic converter in SI Engine emission reduction. D.Karthickeyan ,G.Saravanan -2016

3. Catalytic Converter Materials \& Structure analysis Dr. Ing.habil.bilgesaruhan, German aerospace center., 2015. Future applications to develop materials that are hightemperature stabile and catalytically active at temperatures above $600^{\circ} \mathrm{C}$. These can be complex oxides from binary compounds with perovskite and spinel structures.

4. Earth Materials Englewood Cliffs SPINEL STRUCTURE, Ernst, W. G. Normal spinel structures are usually cubic close-packed oxides with two tetrahedral and one octahedral sites per formula unit.

5. A Detailed Study on CATALYTIC CONVERTER, AayushBawdekar 2014.

\section{Methodology}

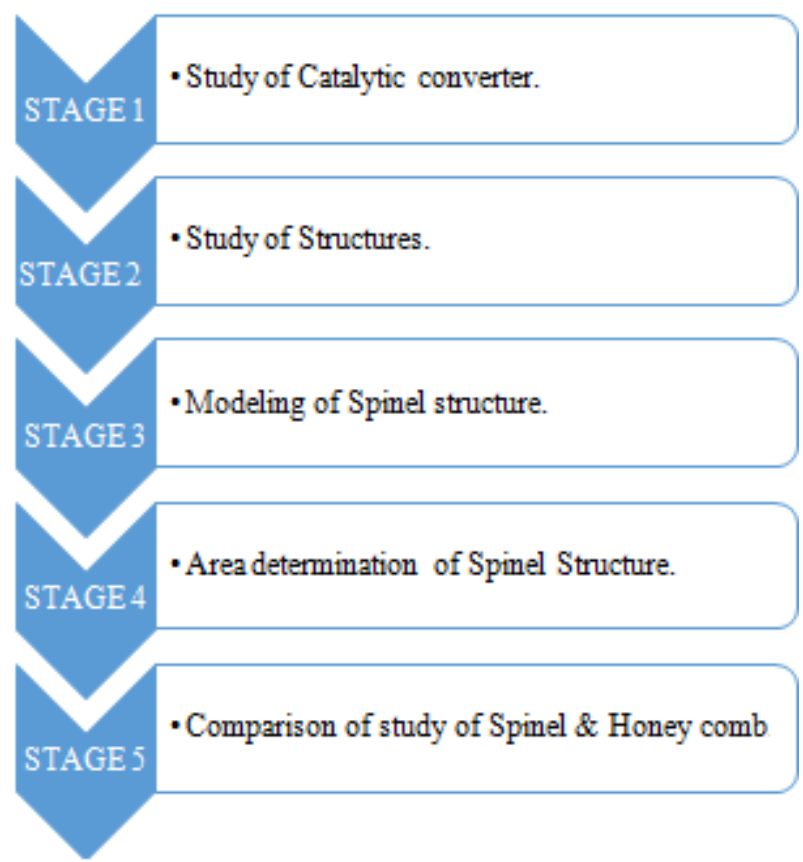

\section{Types of Structures}

Two types of structure are made pellets and honeycomb monoliths. The pellets are porous beads approximately 3 millimeters $(1 / 8$ inch) in diameter. With a single pellet having up to 10 square millimeters of internal pore surface area, one liter of pellets can have up to 500,000 square meters of support surface. The pellet material is often alumina (aluminum oxide, $\mathrm{Al} 2 \mathrm{O} 3$ ). High internal porosity is achieved by carefully burning off the organic additives and by incomplete sintering.

Honeycomb monoliths have 1,000 to 2,000 longitudinal pores approximately one millimeter in size separated by thin walls. The extruded structure is coated with a wash of alumina, which in turn supports the platinum catalyst particles. The surface area of the monolith is typically in the range of one square meter. Monolith supports are much more expensive than pellet supports, but they cause a smaller pressure drop in the exhaust system. Both types of catalyst support, because of their inherent friability, are susceptible to vibration degradation. Containment of the supports is also difficult. A good seal must be achieved and maintained without imposing external stresses on the friable structure.

\subsection{Honey comb Structure}

The converter consists of a porous honeycomb ceramic base material coated with a precious metal catalyst. The honeycomb structure provides high catalyst surface area, which maximizes the contact between the catalysts and the pollutants in the hot exhaust gases. . Monolith supports are much more expensive than pellet supports, but they cause a smaller pressure drop in the exhaust system.Honeycomb materials are widely used where flat or slightly curved surfaces are needed and their high Specific strength is valuable. 


\section{International Journal of Science and Research (IJSR) \\ ISSN (Online): 2319-7064}

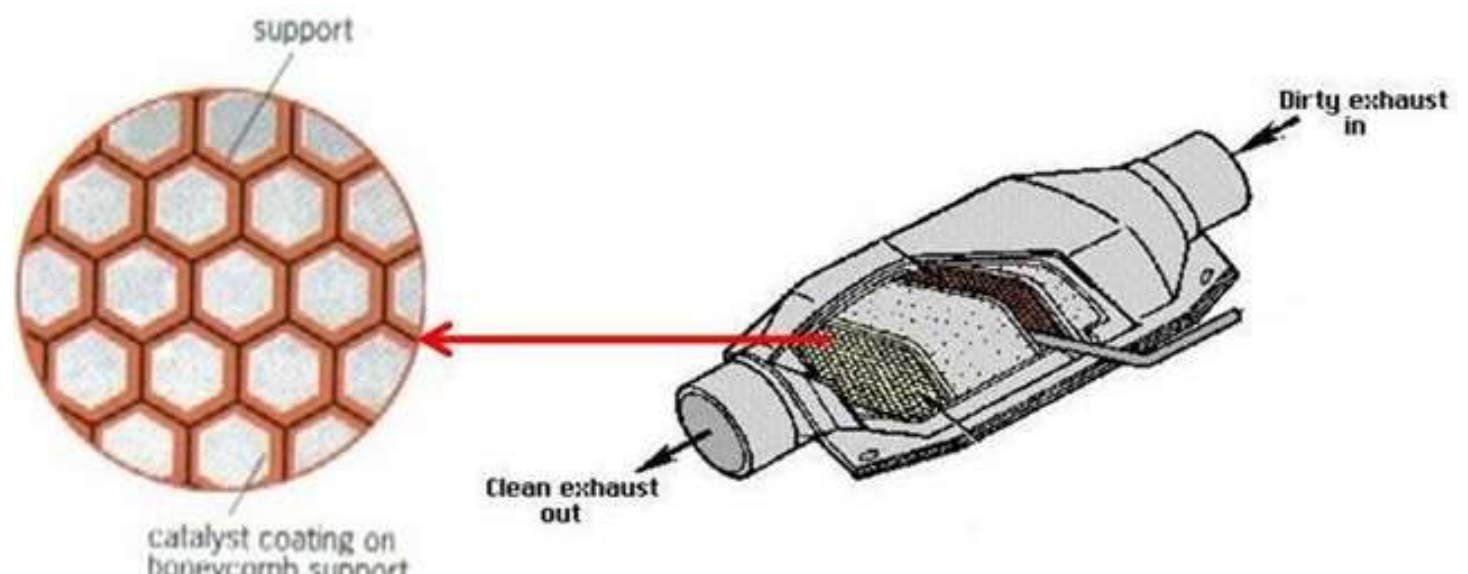

Figure 9.1

\subsection{SPINEL STRUCTURE:}

Normal spinel structures are usually cubic close-packed oxides with two tetrahedral and one octahedral sites per formula unit. The tetrahedral spaces are smaller than the octahedral spaces. $\mathrm{B}^{3+}$ ions occupy half the octahedral holes, while $\mathrm{A}^{2+}$ ions occupy one-eighth of the tetrahedral holes. Mineral spinel $\mathrm{MgAl}_{2} \mathrm{O}_{4}$ has a normal spinel structure.

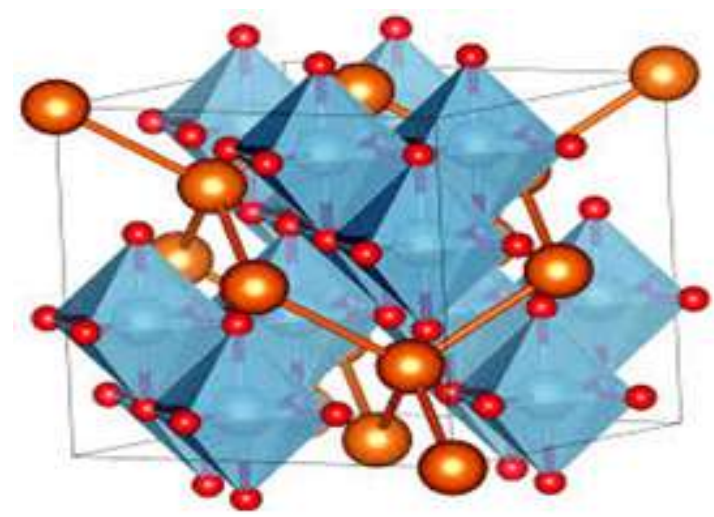

Figure 9.2

10. Modeling of Structure

\section{Modeling Using Solid Works}

\subsection{Honey Comb}

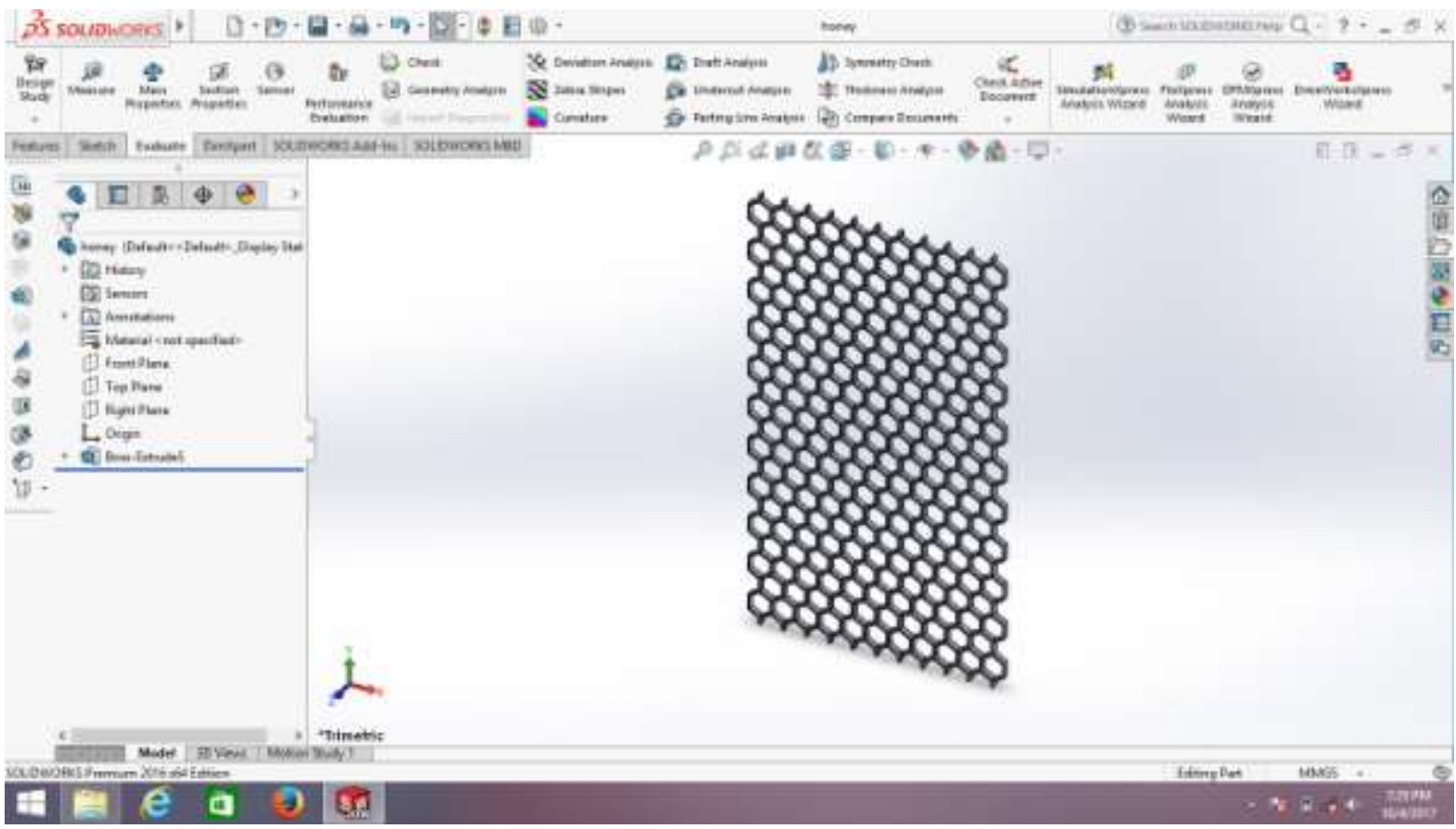

Figure 10.1(a)

10.2 Spinel

Volume 6 Issue 12, December 2017 www.ijsr.net 


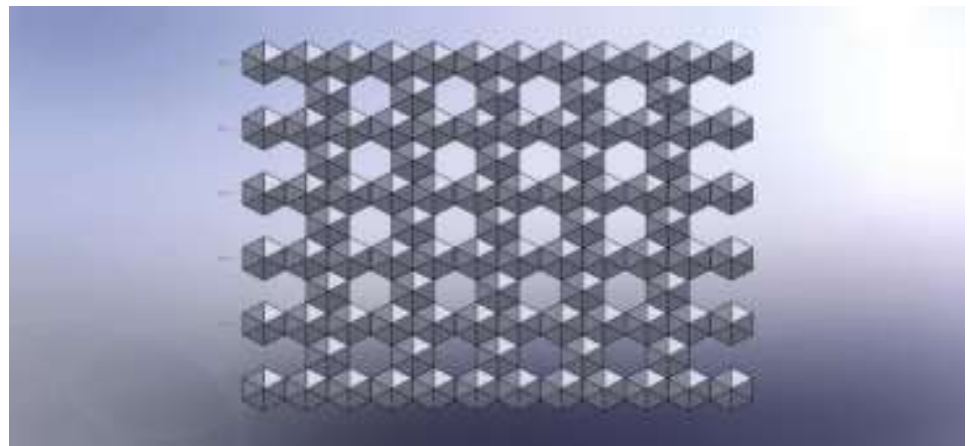

Figure $\mathbf{1 0 . 2}$

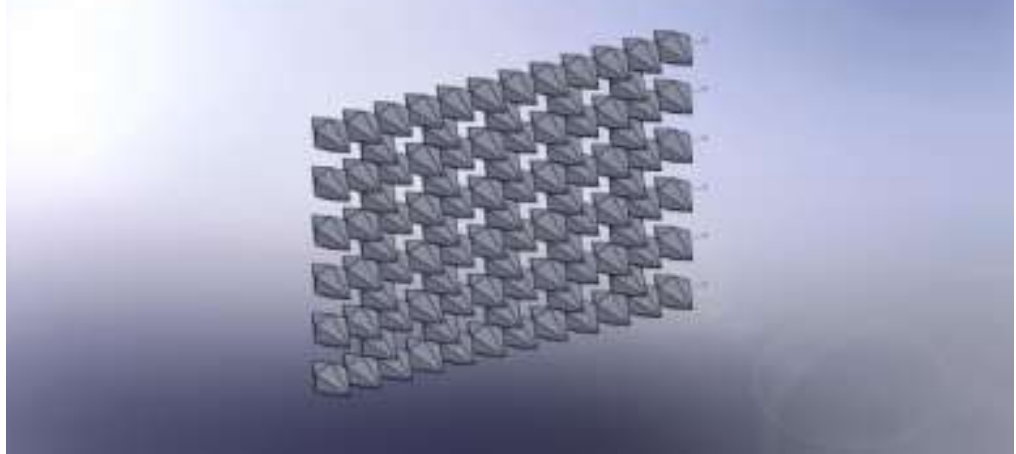

Figure 10.3

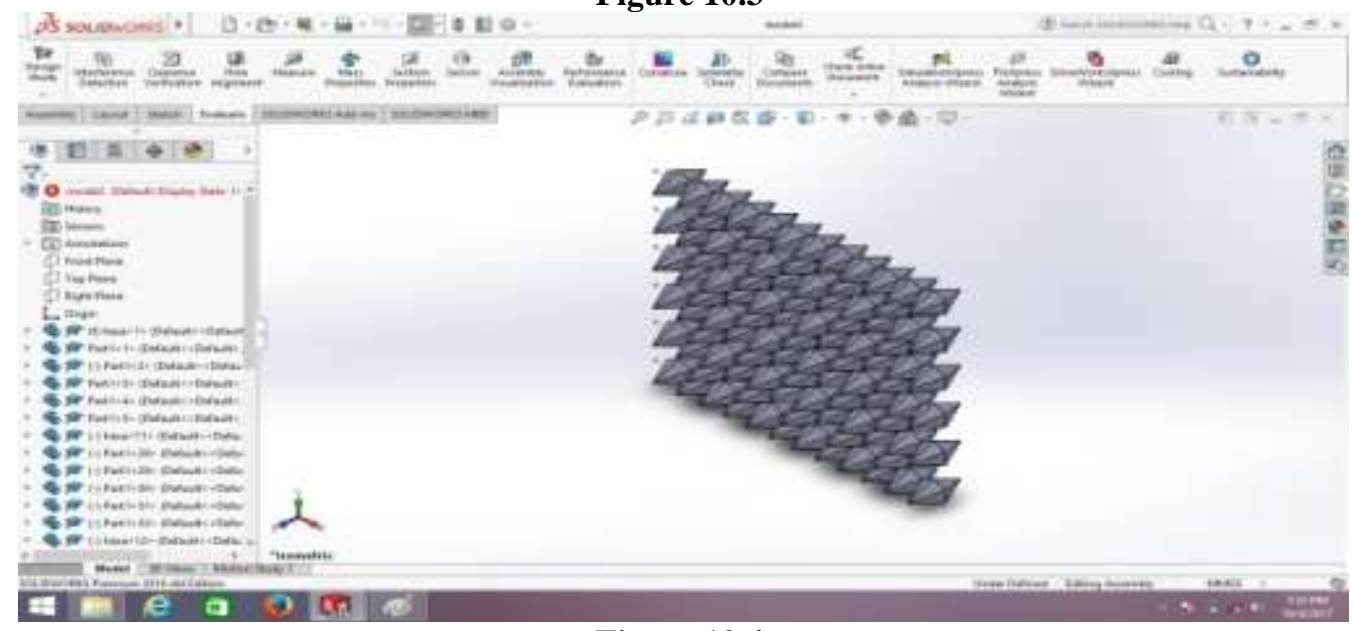

Figure 10.4

\section{Tetra Hedral}

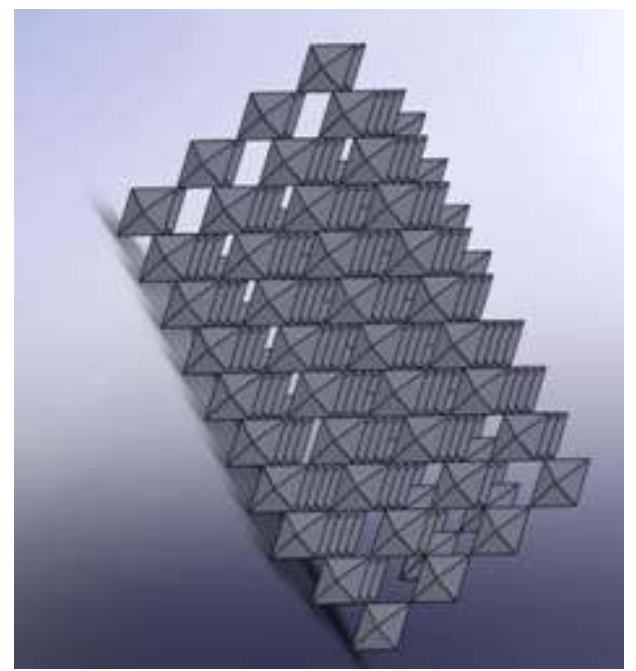

Figure 11.1

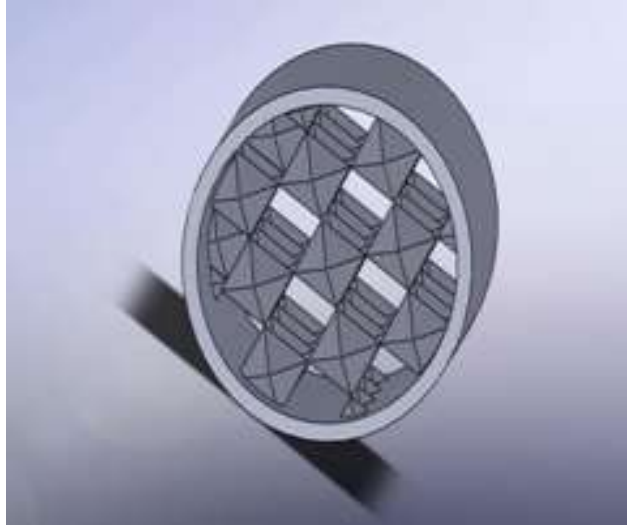

Figure 11.2

\section{Design Aspects of Catalytic Converter}

1) Should provide enough surface area to meet conversion efficiency requirement for both $\mathrm{HC}+\mathrm{NOX}$ and $\mathrm{CO}$.

2) Should not interfere with engine operation.

Volume 6 Issue 12, December 2017

\author{
www.ijsr.net
}

Licensed Under Creative Commons Attribution CC BY 


\section{International Journal of Science and Research (IJSR) \\ ISSN (Online): 2319-7064 \\ Index Copernicus Value (2016): 79.57 | Impact Factor (2015): 6.391}

3) Must meet durability requirements.

4) Heat generated by the catalytic reactions must not raise safety converters.

5) Must fit in the available space.

6) Should be affordable.

\subsection{Design and Analysis of Structure:}

The goal of design is to deliver customer expectations at profitable cost regardless of customer usage, degradation over product life and variation in manufacturing, suppliers, distribution, delivery and installation Since randomness and scatter is a part of reality everywhere, probabilistic design techniques are necessary to engineer quality into designs. The safety factors are derived based on past experience; they do not guarantee safety or satisfactory performance and do not provide sufficient information to achieve optimal use of available resources.

\subsection{Parametric Deterministic FEA Model}

1) The material of the honeycomb and spinel structures is ceramic and it is isotropic, linear elastic and the behavior is within small deflection linear theory limits. The modulus of elasticity is $\mathrm{E}=3500 \mathrm{MPa}$ and Poisson's ratio is 0.34

2) Structural Analysis is sufficient to accurately predict the maximum shear stress.

3) There is no temperature effect on the material properties.

4) The geometry, loading and behavior are symmetric about the horizontal and vertical axes.

\section{Modelling Tools and Procedure}

1) Create two planes having between distances of $5 \mathrm{~mm}$.

2) Create point on it as per regular dimensions and create a prismatic profile.

3) Turn into a solid model.

4) Assemble the part in a linear manner to the length we want.

5) Create a new plane as in bottom and mirror the pattern to bottom.

\subsection{Area Results}

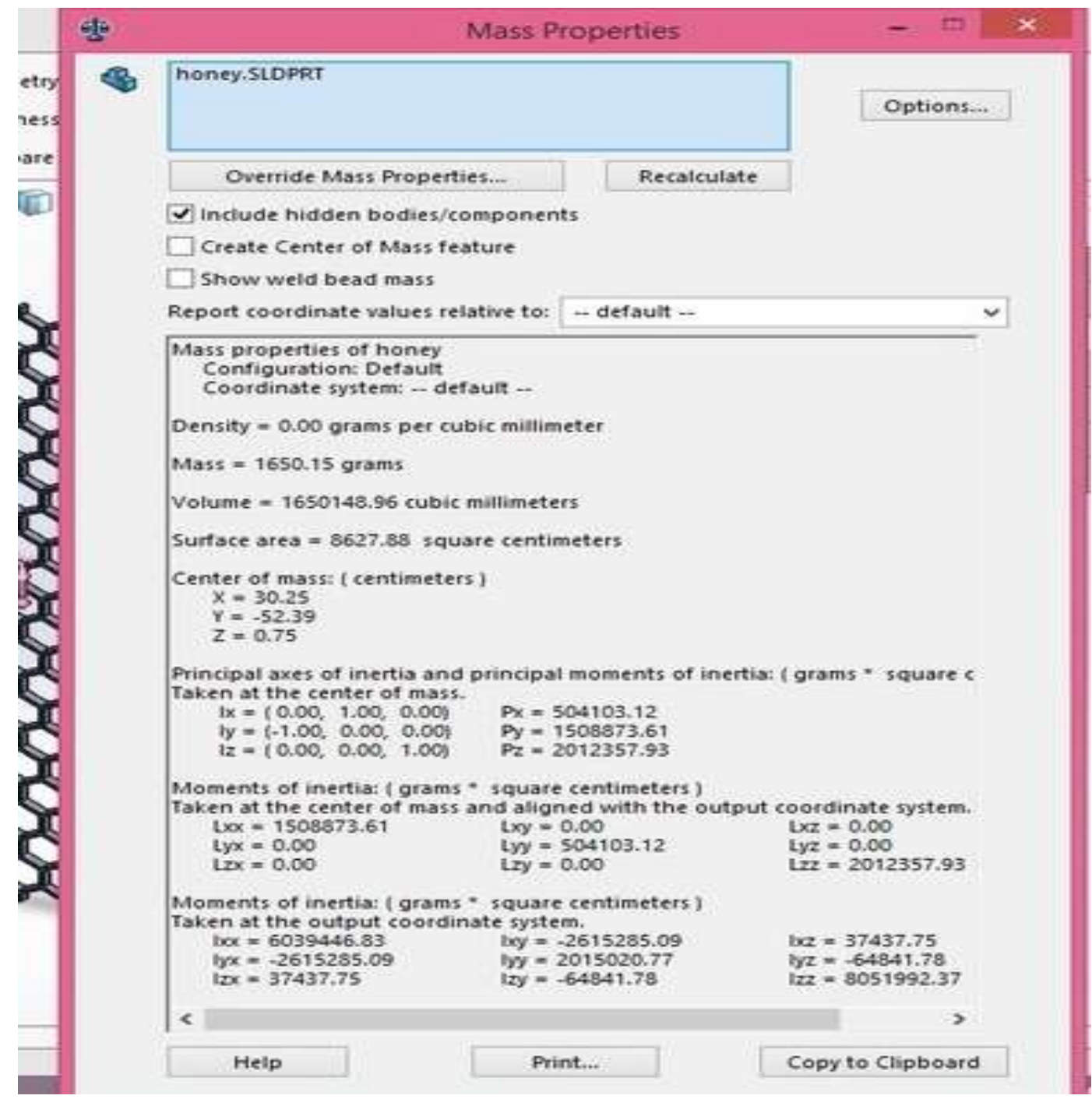

Figure 13.1

Volume 6 Issue 12, December 2017

www.ijsr.net

Licensed Under Creative Commons Attribution CC BY 
International Journal of Science and Research (IJSR)

ISSN (Online): 2319-7064

Index Copernicus Value (2016): 79.57 | Impact Factor (2015): 6.391

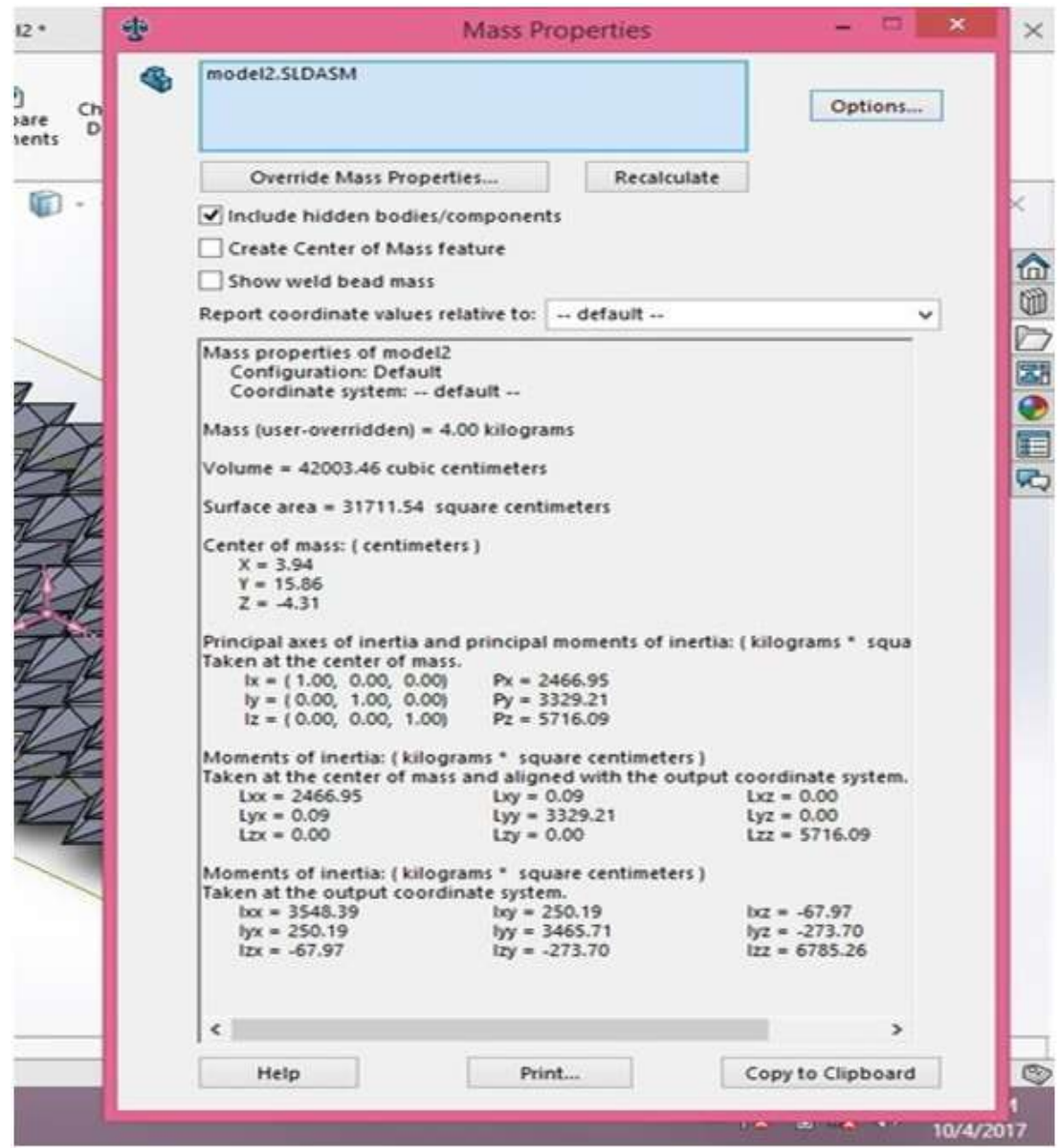

Figure 13.2

13.1.1. Ansys Result

Total Deformation
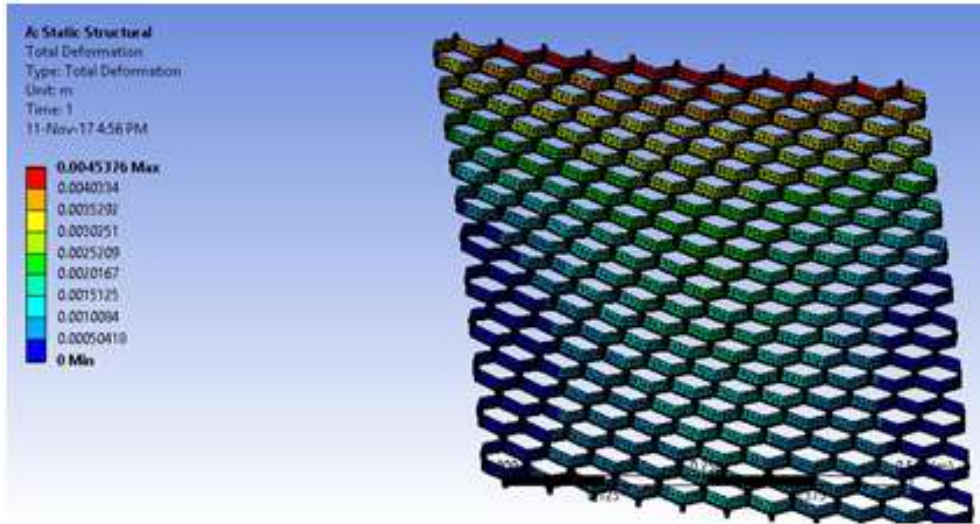

ANSYS

Total Stress

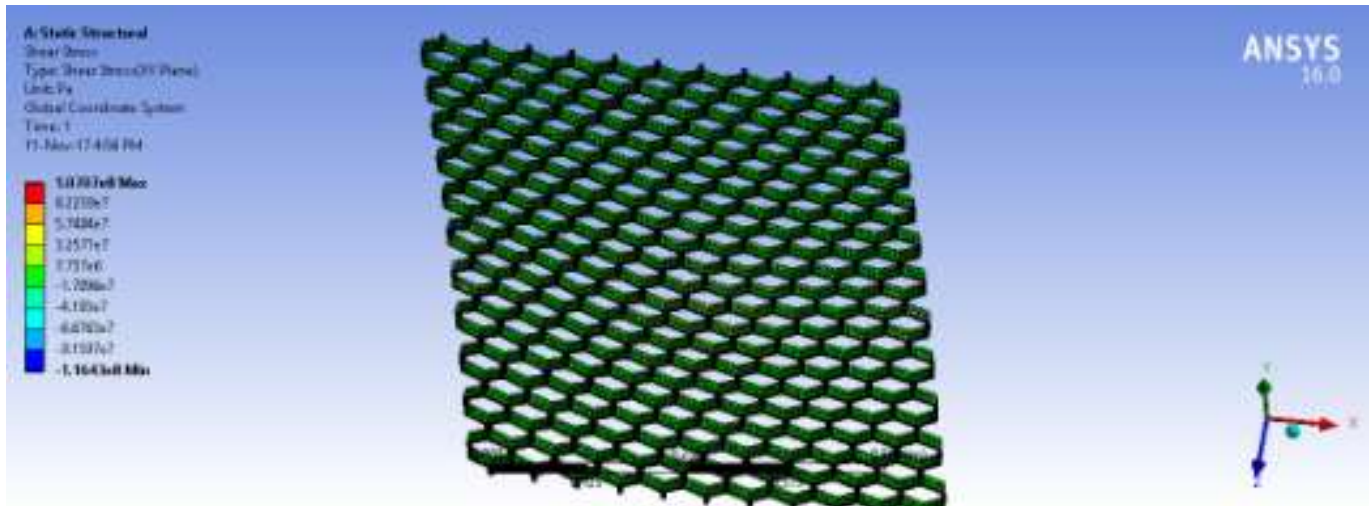

Volume 6 Issue 12, December 2017

www.ijsr.net

Licensed Under Creative Commons Attribution CC BY 


\section{Comparison}

Table 14.1

\begin{tabular}{|l|l|}
\hline Spinel Structure & Honey Comb Structure \\
\hline - Larger area of contact & $\begin{array}{l}\bullet \text { Comparatively lower area of } \\
\text { contact }\end{array}$ \\
\hline $\begin{array}{l}\text { - Higher contact time due } \\
\text { to trapping. }\end{array}$ & $\bullet$ Rapid exhaust gas flow \\
\hline - Higher life time & $\bullet$ Optimum life time \\
\hline - Efficiency is higher & $\bullet$ Efficiency is optimum \\
\hline
\end{tabular}

\section{Data Results}

\section{Table 15.1}

\begin{tabular}{|c|c|c|}
\hline Properties & Spinel & Honey Comb \\
\hline Mass & 4003.46 grams & 1650.15 grams \\
\hline Volume & $\begin{array}{c}\text { 42003.19 cubic } \\
\text { millimeters }\end{array}$ & $\begin{array}{c}16501.96 \text { cubic } \\
\text { millimeters }\end{array}$ \\
\hline $\begin{array}{c}\text { Surface } \\
\text { area }\end{array}$ & $\begin{array}{c}\text { 31711.54 square } \\
\text { centimeters }\end{array}$ & $\begin{array}{c}\text { 8627.88 square } \\
\text { centimeters }\end{array}$ \\
\hline
\end{tabular}

\section{Inference}

- Surface area of spinel is increased 4 times when compared with honeycomb structure.

- So due to contact area rise, the emission reduction also little improved.

\section{Future Works}

It is advised to change the structure of catalytic converter. And also composite material usage in place of ceramic can improve the life of converter in heavy applications for industrial purposes.

\section{References}

[1] Effect of creating turbulence on performance of catalytic converter. Mohit Bhadwal - 2015.

[2] Catalytic Converter Materials \& Structure analysis, Dr.Ing.habil.bilgesaruhan, German aerospace center., 2015.

[3] Earth Materials Englewood Cliffs SPINEL STRUCTURE, Ernst, W. G.

[4] J. K. Dunleavy, Platinum Metals Rev., 2006, 50, (2), 110.

[5] A Detailed Study on CATALYTIC CONVERTER ,AayushBawdekar 2014.

[6] Multifunctional Emission Reducing Coatings.,Prof.Dr.Ing. Uwe Schulz .German aerospace center. 2015

[7] Transient modelling of flow distribution in automotive catalytic converters .D.N. Tsinoglou, G.C. Koltsakis., 2004.

[8] The Effect of De-Greening and Pre-Treatment on Automotive Catalyst Performance.Claire McAtee, Geoffrey McCullough, Roy Douglas, Laura Glover2011.

[9] NOx Selective Catalytic Reduction (SCR)-Emission Technology for India,Kumar, P., AnirudhJaipuria, Umashankar, N, Lakshminarayanan, P.A.,2009 .

[10]Performance Analysis of Limestone Coated WIREMESH Catalytic Converter for Emission Control of C.I Engine Jay M. Parmar Prof. Keyur D. Tandel

\section{Softwares Used}

[11] Solid works 2016.

[12] Ansys 17.0.

Volume 6 Issue 12, December 2017 